\title{
Temporal and spatial variation of soil moisture of small watershed in gully catchment of the Loess Plateau of China
}

\author{
Dong Qiguang ${ }^{1,2,3,4^{*}}$, Han Jichang ${ }^{1,2,3,4}$, Lei $\mathrm{Na}^{1,2,3,4}$, He Jing ${ }^{1,2,3,4}$, Sun Zenghui ${ }^{1,2,3,4}$, Xiong Yufei ${ }^{1,2,3,4}$, Li Ya'nan ${ }^{1,2,3,4}$ \\ ${ }^{1}$ Shaanxi Provincial Land Engineering Construction Group Co., Ltd., 710075 Xi'an, China \\ ${ }^{2}$ Institute of Land Engineering and Technology, Shaanxi Provincial Land Engineering Construction Group Co., Ltd., 710075 Xi'an, \\ China \\ ${ }^{3}$ Key Laboratory of Degraded and Unused Land Consolidation Engineering, the Ministry of Natural Resources, 710075 Xi' an, China \\ ${ }^{4}$ Shaanxi Provincial Land Consolidation Engineering Technology Research Center, 710075 Xi'an, China
}

\begin{abstract}
The temporal and spatial variation characteristics of soil moisture in typical slope and gully of Jiulongquangou small watershed were studied in the hilly and gully region of the Loess Plateau of China. The variation of soil moisture in the $0-30 \mathrm{~cm}$ layer on the surface of the hilly and gully region of the Loess Plateau is greater than the variation of soil moisture in each layer between 40 and $100 \mathrm{~cm}$. In the study area, the model parameters such as coefficient of variation $(\mathrm{Cv})$, nugget $(\mathrm{C} 0)$, sill $(\mathrm{C} 0+\mathrm{C})$, spatial degrees of freedom $(\mathrm{C} 0 /(\mathrm{C}+\mathrm{C} 0))$ and variable change can be used to quantitative analysis the spatial varying law. On the slope surface, the average soil water content and the coefficient of variation are negatively correlated, and can be approximated by an exponential function, while the two are positively correlated in the gully.
\end{abstract}

\section{Introduction}

As an important variable for understanding and predicting a range of hydrological processes including flooding, erosion, solute transport and land-atmosphere interactions, soil moisture profoundly affects the ecological environment construction and specific farm planning and management ${ }^{[1-3]}$. There are a number of factors such as the interaction of precipitation, soil depth, vegetation and topography, which will lead to high variation of soil moisture ${ }^{[4-5]}$. The knowledge of the characteristics of the variability is important for understanding and predicting the hydrological processes to reduce the erosion and raising the utilization ratio of water $^{[6]}$.

The spatial and temporal variation and dominant factors of soil moisture have been studied to understand soil moisture dynamics in a spatial context, and to determine controlling factors and scaling properties in recent years ${ }^{[7-8]}$. In the hilly and gully region of the Loess Plateau, topography, vegetation cover and precipitation play key roles on the spatial distribution of soil moisture in this area.

\section{Materials and methods}

\subsection{Description of study area and data set}

The study area is located in Jiulongquangou, Nanniwan Town, Baota District, Yan'an City, Shaanxi Province. It belongs to the loess hilly and gully region of northern Shaanxi. The channel in the study area is $9.8 \mathrm{~km}$ long from north to south. The elevation of the river course decreased from $1170 \mathrm{~m}$ to $1093 \mathrm{~m}$ from south to north, with an average ratio of $0.78 \%$, and the valley width was generally between $250 \mathrm{~m}$ and $500 \mathrm{~m}$. The region has a semiarid continental climate with the average annual precipitation of $573 \mathrm{~mm}$. The annual average temperature is $9{ }^{\circ} \mathrm{C}$, the average frost-free period is 179 $\mathrm{d}$, the average annual water surface evaporation is about $1000 \mathrm{~mm}$, the land evaporation is $550 \mathrm{~mm}$, and the drought index is 1.75. The spatial and temporal distribution of rainfall is uneven, the seasonal variation is large, and the utilization rate is low.

The contour map of the study area and the sampling point position are shown in Figure 1. This study defines six slope positions according to the elevation and location, which are: top of slope, upper slope, middle slope, lower slope, foot of slope and gully. 18 sampling sites were selected for analyzing the soil moisture content in the study area (Fig. 1). The soil moisture was measured by TRIME-TDR with different depths from 0 to $100 \mathrm{~cm}$ at intervals of $10 \mathrm{~cm}$.

\footnotetext{
* Corresponding author: dq-guang@163.com
} 


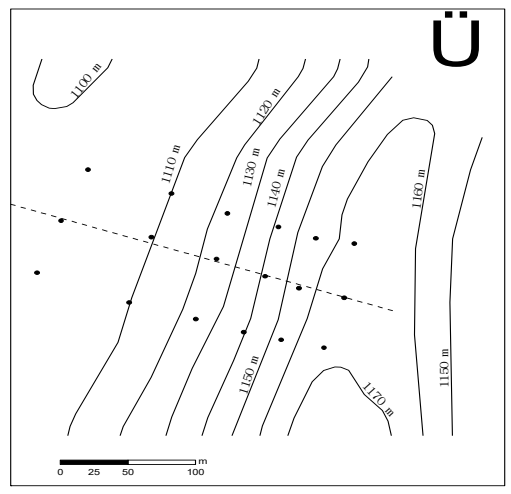

Fig. 1. Sampling point location and study area contour map in Jiulongquangou catchment

\subsection{Method of analysis}

Calculations of some statistic variables used in the study are demonstrated as follows: Assume that the soil moisture content of sampling point $\mathrm{i}$, soil layer $\mathrm{j}$ and sampling number $\mathrm{k}$ is expressed as $\mathrm{Mi}, \mathrm{j}, \mathrm{k}$. $\mathrm{Np}$ is the number of sampling points, which is 18 in this study; N1 represents the number of soil sampling layers or soil depth, which is 10 in this study; Nt is the number of samplings, which is 7 in this study (Collecting samples once a month from May. to Nov.). (Mi):

Mean soil moisture content on sampling position i

$$
M_{i}=\frac{1}{N_{l} \times N_{t}} \sum_{j=1}^{N_{l}} \sum_{k=1}^{N_{t}} M_{i, j, k}
$$

Mean soil moisture content at soil layer $\mathrm{j}(\mathrm{Mj})$ :

$$
M_{j}=\frac{1}{N_{p} \times N_{t}} \sum_{i=1}^{N_{p}} \sum_{k=1}^{N_{t}} M_{i, j, k}
$$

Spatial variation $(\mathrm{CV})$ of time-averaged soil moisture at soil layer $\mathrm{j}$ :

$$
C V_{j}=\frac{1}{M_{j}} \sqrt{\frac{\sum_{i=1}^{N_{p}}\left(M_{i, j}-M_{j}\right)^{2}}{N_{p}-1}}
$$

Spatial variability $(\mathrm{CV})$ of layer-averaged soil moisture on measurement occasion $\mathrm{k}$ :

$$
C V_{k}=\frac{1}{M_{k}} \sqrt{\frac{\sum_{i=1}^{N_{p}}\left(M_{i, k}-M_{k}\right)^{2}}{N_{p}-1}}
$$

The geostatistical analysis of soil water variability was analyzed using the semi-variogram of Arcgis 9.3, data analysis using Excle 07, SPSS 13.0, drawing by Origine 8.0 and Sigmplot 10.0 .

\section{Results}

\subsection{Statistical characteristics of soil moisture}

It can be seen from Table 1 that the coefficient of variation of $0-100 \mathrm{~cm}$ soil moisture is between $20 \%$ and $30 \%$, which is moderately variable. The soil moisture variability at 10,20 and $30 \mathrm{~cm}$ is relatively large, all is above $25 \%$. From that we get that the variation of soil moisture in the $0-30 \mathrm{~cm}$ layer on the surface of the hilly and gully region of the Loess Plateau is greater than the variation of soil moisture in each layer between 40 and $100 \mathrm{~cm}$. Soil moisture of surface layer $(<30 \mathrm{~cm})$ is mainly affected by topographic conditions such as slope position and slope and evaporation under microclimate conditions, the influence of force, as the soil layer deepens, the soil moisture is reduced by evaporation, and the transpiration of vegetation is increased ${ }^{[9-10]}$. It can be concluded that in the $0-100 \mathrm{~cm}$ soil layer, the spatial difference $(<30 \mathrm{~cm})$ of soil moisture caused by the topography and microclimate of the study area is relatively large while the spatial difference of soil moisture caused by vegetation is relatively small $(>30$ $\mathrm{cm})$.

Table 1. Average soil moisture contents in different depth ranges

\begin{tabular}{|c|c|c|c|c|c|}
\hline \multirow{2}{*}{ Soil depth/cm } & \multicolumn{3}{|c|}{ soil moisture content/\% } & \multirow{2}{*}{$\begin{array}{c}\text { Standard } \\
\text { deviation/\% }\end{array}$} & $\begin{array}{c}\text { Coefficient of } \\
\text { variation/\% }\end{array}$ \\
\cline { 2 - 4 } & Maximum & Minimum & Mean & 3.57 & 28.00 \\
\hline 10 & 19.45 & 7.36 & 12.76 & 4.10 & 30.01 \\
\hline 20 & 21.71 & 7.31 & 13.66 & 3.47 & 25.53 \\
\hline 30 & 19.04 & 7.32 & 13.58 & 3.67 & 26.75 \\
\hline 40 & 21.03 & 7.45 & 13.70 & 4.08 & 29.60 \\
\hline 50 & 24.30 & 9.27 & 13.93 & 3.88 & 27.85 \\
\hline 60 & 23.67 & 9.65 & 13.74 & 3.59 & 26.10 \\
\hline 70 & 22.34 & 9.92 & 13.96 & 3.20 & 22.90 \\
\hline 80 & 21.13 & 10.09 & 14.36 & 3.33 & 23.19 \\
\hline 90 & 22.60 & 10.00 & 14.75 & 3.89 & 26.36 \\
\hline 100 & 26.36 & & & 13.80 & \\
\hline
\end{tabular}

the variation function when inferring the variation

\subsection{Spatial variability of soil moisture of different depths}

Due to the limited number of sampling points, a reasonable theory model is necessary to fit the curve of characteristics of soil moisture in the study area. The model parameters such as coefficient of variation $(\mathrm{Cv})$, nugget $(\mathrm{C} 0)$, sill $(\mathrm{C} 0+\mathrm{C})$, spatial degrees of freedom $(\mathrm{C} 0 /(\mathrm{C}+\mathrm{C} 0))$ and variable change can be used to quantitative analysis the spatial varying law. The nugget 
reflect the randomness of the variable in study area mainly caused by the variability and experimental error when the variable is less than the sampling scale; the sill expresses the greatest degree of variation of the variables; the variable change represents the maximum influence between the variables; the spatial degrees of freedom means the proportion of random variation in total variation, when the value is large, the degree of spatial heterogeneity caused by random parts is high, the spatial heterogeneity caused by the spatial autocorrelation part is high. From Table 2 we can see the spatial degree of freedom is less than 0.25 indicates that the system has a strong spatial autocorrelation, between 0.25 to 0.75 indicates that the system has a medium spatial autocorrelation, greater than 0.75 indicates that the system has weak spatial autocorrelation ${ }^{[5,10]}$.
The nugget value of soil moisture is obviously larger at $0-30 \mathrm{~cm}$, and the increase of nugget value is mainly affected by topography and geomorphology and precipitation, which causes the internal variation of soil moisture to be smaller than the sampling scale.

Although the variability of $0-30 \mathrm{~cm}$ soil moisture is large, the variability of $30-100 \mathrm{~cm}$ soil moisture is small, the variable range of the soil moisture at the regional scale is larger in $0-30 \mathrm{~cm}$, and is smaller in $30-100 \mathrm{~cm}$. The reason is that the average value of surface soil moisture is small, and the absolute difference between points in the study area at this level is relatively small.

Soil moisture in each layer has strong spatial autocorrelation, all spatial degrees of freedom is less than $25 \%$, It is indicated that the random factors have little effect on soil moisture, and the spatial variation is mainly caused by the spatial autocorrelation of natural factors such as topography, land use and vegetation.

Table 2. Variation parameters of water content in different soil layers

\begin{tabular}{|c|c|c|c|c|c|c|c|}
\hline Depth/cm & Nugget C0 & $\begin{array}{c}\text { Partial Sill } \\
\mathrm{C}\end{array}$ & Step length/m & $\begin{array}{c}\text { Sill } \\
\mathrm{C} 0+\mathrm{C}\end{array}$ & Variable range/m & $\begin{array}{c}\text { Spatial freedom } \\
\mathrm{C} 0 /(\mathrm{C}+\mathrm{C} 0)\end{array}$ & $\mathrm{P}(\mathrm{K}-\mathrm{S})$ \\
\hline 10 & 2.05 & 18.51 & 21.34 & 20.57 & 187.81 & $9.98 \%$ & 0.973 \\
\hline 20 & 3.73 & 32.61 & 24.02 & 36.33 & 288.26 & $10.25 \%$ & 0.941 \\
\hline 30 & 2.02 & 25.49 & 24.02 & 27.51 & 288.26 & $7.35 \%$ & 0.802 \\
\hline 40 & 1.51 & 13.27 & 15.93 & 14.78 & 127.54 & $10.23 \%$ & 0.994 \\
\hline 50 & 0.02 & 16.71 & 12.48 & 16.72 & 99.57 & $0.10 \%$ & 0.776 \\
\hline 60 & 0.00 & 15.40 & 10.94 & 15.40 & 94.94 & $0.00 \%$ & 0.723 \\
\hline 70 & 0.00 & 12.78 & 15.49 & 12.78 & 94.94 & $0.00 \%$ & 0.912 \\
\hline 80 & 0.00 & 9.30 & 14.55 & 9.30 & 94.94 & $0.00 \%$ & 0.928 \\
\hline 90 & 0.00 & 9.39 & 13.38 & 9.39 & 99.57 & $0.00 \%$ & 0.911 \\
\hline 100 & 0.01 & 11.85 & 13.95 & 11.86 & 103.70 & $0.10 \%$ & 0.816 \\
\hline
\end{tabular}

\subsection{Comparison of variability of soil moisture at different slope positions}

The soil moisture time-averaged variation coefficient of each position depth soil layer is shown in Fig. 2. It can be seen from the figure that the soil moisture coefficient of variation of each soil layer is smaller $(<20 \%)$ at the top and the upper slope, this is because soil moisture of the two places is mainly supplied directly by precipitation, and the relatively gentle terrain and single vegetation distribution made relatively uniform soil water distribution. At the middle slope and lower slope the slope is large, the terrain is more complicated, the micro-topography is obvious, and the variability of soil moisture is large $(>20 \%)$ in $0-20 \mathrm{~cm}$, the soil moisture variability is less under $20 \mathrm{~cm}$, indicating that the microtopography mainly affects the redistribution of surface soil moisture at this two slope, the active layer of moisture change is mainly $0-20 \mathrm{~cm}$ soil layer ${ }^{[11]}$. At the foot of the slope and the gully, the soil moisture variation is obvious on the depth of $40-70 \mathrm{~cm}$, but the soil moisture in the surface layer is not much different. One of the reasons is that in the bottom of the slope and the channel, the source of soil moisture supply is the direct recharge of precipitation. The other reason is the lateral recharge from the slope, which is extremely uneven under the influence of topographic conditions.

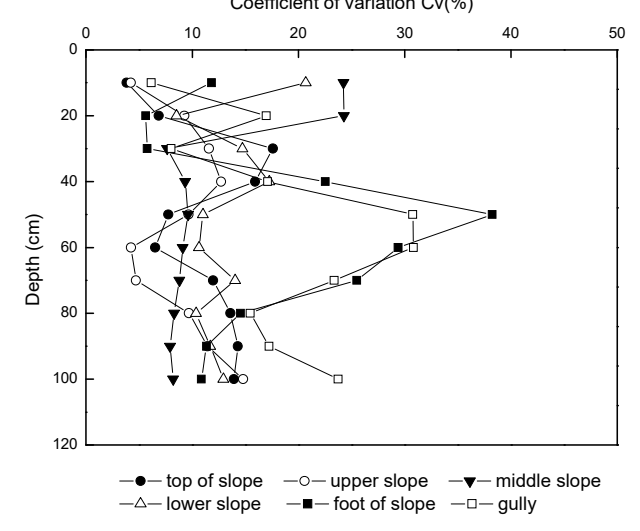

Fig. 2. Profile distribution diagrams of Soil moisture coefficient of variation

An exponential relationship, $\quad \mathrm{CV}=\mathrm{a} \quad \exp ^{\mathrm{b}}{ }^{\theta}$ ${ }^{j, t[12]}$ described the relationship between mean soil moisture and spatial variability, where $\mathrm{CV}$ is the coefficient of variation, $a$ and $b$ are the parameters, and $\bar{\theta}$ $\mathrm{j}, \mathrm{t}$ is the mean soil moisture of the slope position. Average soil moisture and coefficient of variation have a negative impact relationship at top of slope, upper slope and middle slope. Table 3 shows the relationship between the mean soil moisture and the coefficient of variation. Although fitting accuracy is relatively low 
because of the fewer samples, these negative relationships are consistent with Choi's soil moisture experiments. However, at lower slope and foot of slope the relationship and the trend is not obvious, even average soil moisture and coefficient of variation have a positive impact relationship at the gully. The reason may be that as the slope decreases, the soil moisture is recharged by more water from upper slope, the supply route is the more complicated. At the gully, the basic value of soil moisture content is higher, except for direct rainfall recharge, due to the influence of upper vegetation and topography, the runoff recharge received by different parts is different, which leads to soil moisture variation and average moisture content have a positive relationship.

Table 3. Fitting parameters of average soil moisture and coefficient of variation under different slope positions

\begin{tabular}{|c|c|c|c|c|c|c|}
\hline $\begin{array}{c}\text { Fitting } \\
\text { parameter }\end{array}$ & Top of slope & Upper slope & Middle slope & Lower slope & Foot of slope & Gully \\
\hline $\mathrm{a}$ & 178.0600 & 241.3000 & 138.3500 & 43.2000 & 50.7300 & 0.1700 \\
\hline $\mathrm{b}$ & -0.2602 & -0.2736 & -0.1912 & -0.0626 & -0.0528 & 1.0000 \\
\hline $\mathrm{R}^{2}$ & 0.6744 & 0.6327 & 0.5933 & 0.4379 & 0.3641 & 0.6093 \\
\hline
\end{tabular}

5. Zhang, J., Su, Y., Chen, H., Kong, X., Zhang, W., \&

\section{Conclusions}

The average soil water content increases with the depth of the soil layer. The spatial variability of soil water content at different depths showed that the $0-20 \mathrm{~cm}$ variability was the strongest; the variability below $80 \mathrm{~cm}$ was weak. Due to the water collecting effect of the gully and the recharge by the interflow, the coefficient of variation of the $40-70 \mathrm{~cm}$ deep soil layer is larger at the foot of slope and gully. The average soil moisture and coefficient of variation can be fitted by an exponential function, and they have a negative correlation at the top of slope, upper slope and middle slope. Conversely, at the gully, they have a positive correlation.

\section{Acknowledgement}

This study was supported by Fundamental Research Funds for the Central Universities, CHD (No.300102279502) and the National key research and development plan of China (No. 2017YFC0504700).

\section{References}

1. Western, A. W., Zhou, S. L., Grayson, R. B., Mcmahon, T. A., Bloschl, G., \& Wilson, D. J. . Spatial correlation of soil moisture in small catchments and its relation to dominant spatial hydrological processes. Journal of Hydrology, 286(2004), 113-134.

2. Rosenbaum, U., Bogena, H. R., Herbst, M., Huisman, J. A., Peterson, T. J., \& Weuthen, A., et al. . Seasonal and event dynamics of spatial soil moisture patterns at the small catchment scale. Water Resources Research, 48(2012), 3472-3476.

3. Qiu, Y., Fu, B., Wang, J., \& Chen, L. . Spatial variability of soil moisture content and its relation to environmental indices in a semi-arid gully catchment of the loess plateau, china. Journal of Arid Environments, 49(2001), 723-750.

4. Robock, A., Schlosser, C.A., Vinnikov, K.Y., Speranskaya, N.A. \& Entin, J.K.. Evaluation of AMIP soil moisture simulations. Global and Planetary Change, 19(1998), 181-208.
Zhang, J., et al. . Spatial distribution and influencing factor of soil moisture in typical depression area of karst region. Acta Ecologica Sinica, 239(2014), 1-6.

6. Western, A. W., Blöschl, G., \& Grayson, R. B. . Geostatistical characterisation of soil moisture patterns in the tarrawarra catchment. Journal of Hydrology, 205(1998), 20-37.

7. Corradini, C. Soil moisture in the development of hydrological processes and its determination at different spatial scales. J. Hydrol. 516(2014), 1-5.

8. Montzka, C., Bogena, H.R., Weihermuller, L., Jonard, F., Bouzinac, C., Kainulainen, J., Balling, J.E., Loew, A., Dall'Amico, J.T., Rouhe, E., Vanderborght, J., Vereecken, H. Brightness temperature and soil moisture validation at different scales during the SMOS validation campaign in the Rur and Erft catchments, Germany. IEEE Trans. Geosci. Remote Sens. 51(2013), 1728-1743.

9. Zhang, Q., Liu, Y., Yang, Q., Wang, L., Chonghui, M. O., \& Jingzhong, L. I.. Analysis of the spatial variability of soil moisture in degrading alpine meadowin the qilian mountains. Journal of Glaciology \& Geocryology, 36(2014), 88-94.

10. Wang, Y. Q., Shao M. A., Liu Z. P.. Spatial variability of soil moisture at a regional scale in the Loess Plateau. Advances in Water Science, 23(2012), 310-316.

11. Lu, B. C., Xue, Z. D., Zhu, Q. K., \& Li, H. K. . Soil water in micro-terrain on sunny and semi-sunny slopes. Bulletin of Soil \& Water Conservation.29(2009), 62-65.

12. Choi, M., \& Jacobs, J. M. Spatial soil moisture scaling structure during soil moisture experiment 2005. Hydrological Processes, 25(2015), 926-932. 